\title{
Opportunities for Switzerland to Contribute to the Production of Algal Biofuels: the Hydrothermal Pathway to Bio-Methane
}

\author{
Mariluz Bagnoud-Velásquez, ${ }^{\text {ab§ }}$ Dominik Refardt, ${ }^{c \S}$ François Vuille, ${ }^{d}$ and Christian Ludwigab
}

\begin{abstract}
Microalgae have a significant potential to be a sustainable source of fuel and thus are of interest in the transition to a sustainable energy system, in particular for resource-dependent countries such as Switzerland. Independence of fossil fuels, considerable reduction of $\mathrm{CO}_{2}$ emissions, and abandoning nuclear energy may be possible with an integrated system approach including the sourcing of biofuels from different types of biomass. Today, a full carbon-to-fuel conversion is possible, and has been recently demonstrated with an advanced hydrothermal technology. The potential to develop algal biofuels is viewed as high thanks to the possibility they offer to uncouple bioenergy from food production. Nevertheless, technological breakthroughs must take place before commercial production becomes a reality, especially to meet the necessary cost savings and efficiency gains in the algae cultivation structure. In addition, an integrated management of waste resources to promote the nutrient recovery appears today as imperative to further improve the economic viability and the environmental sustainability of algal production. We provide here a review that includes the global technological status of both algae production and their conversion into biofuels in order to understand first the added value of algal energy in general before we focus on the potential of algae to contribute specifically to the Swiss energy system to the horizon 2050. In this respect, the hydrothermal conversion pathway of microalgal biomass into synthetic natural gas (SNG) is emphasized, as research into this technology has received considerable attention in Switzerland during the last decade. In addition, SNG is a particularly relevant fuel in the Swiss context due to the existing gas grid and to the opportunity it offers to cover a wide spectrum of energy applications, in particular cogeneration of heat and electricity or use as a transport fuel in the growing gas car fleet.
\end{abstract}

Keywords: Biofuel · Energy Strategy 2050 - Microalgae · Supercritical water gasification · Synthetic natural gas (SNG)

\section{Introduction}

Understanding how algae can play a relevant role in the future Swiss energy system is complex and the approach requires a high degree of multidisciplinarity. This relates in particular to the Swiss energy transition from today to 2050 whose key challenges are phasing out nuclear power production and reducing carbon emissions, while maintaining a high level

\footnotetext{
${ }^{\star}$ Correspondence: M. Bagnoud-Velásquez ${ }^{\mathrm{ab}}$

E-mail: mariluz.bagnoud@epfl.ch

aÉcole Polytechnique Fédérale de Lausanne (EPFL)

School of Architecture, Civil and Environmental

Engineering (ENAC-IIE)

$\mathrm{CH}-1015$ Lausanne

bPaul Scherrer Institute (PSI)

General Energy Research Department (ENE-LBK)

$\mathrm{CH}-5232$ Villigen PS

'Zurich University of Applied Sciences

School of Life Sciences and Facility Management

Institute of Natural Resource Sciences

$\mathrm{CH}-8820$ Wädenswil

dÉcole Polytechnique Fédérale de Lausanne (EPFL)

Centre de l'énergie, Château En Bassenges

$\mathrm{CH}-1015$ Lausanne

$\S$ These authors equally contributed to the work
}

of energy security and country prosperity. In this context, energy from biomass (bioenergy) is an interesting option.

In accordance with the Swiss Coordinated Energy Research action plan, ${ }^{[1]}$ the creation of research networks between higher education institutions, the Swiss Competence Centers for Energy Research (SCCERs), was proposed by the Swiss Federal Council and the Parliament as a means to meet future challenges in energy supply. Eight SCCERs operate in different areas of energy research. SCCER BIOSWEET, the Swiss Competence Center for Energy Research in the field of bioenergy, postulates the vision of increasing the contribution of bioenergy in Switzerland with an additional 100 PJ. The unused domestic sustainable potential for biomass is estimated to be only around 40 PJ today, while the sustainable potential was estimated at 82 PJ.[2,3] In order to go beyond this estimated bioenergy potential in Switzerland and meet the 100 PJ foreseen by the SCCER BIOSWEET, growing microalgae feedstock was suggested as a 'breakthrough' technology. This sugges- tion is tackled together with Swiss industry and international partners. Thus, the SCCER BIOSWEET vision foresees one third of the additional $100 \mathrm{PJ}$ to be covered by woody biomass, another third contributed by agricultural wastes and residues and a last third from algae.[3]

If biomass is to become an efficient and widespread source of renewable energy, more efficient end-use technologies need to become established on the market. Concerning biofuels from microalgae, such a technology should be readily adaptable to accept various types of intermediate products of an algal biorefinery. Recently, the Swiss bioenergy research sector assisted in one of these successful cases: the hydrothermal treatment of microalgae to produce synthetic natural gas (SNG (methane)) was technically demonstrated in the SunCHem project.[4,5] Motivated by the great impact this has created, this review aims at fostering further discussion on i) the potential of microalgae as a bioenergy feedstock, ii) the most promising algae to biofuel routes, iii) the techno-economics of these different technologies and routes 
in the Swiss context, and iv) the question how Switzerland can best apply its R\&D strengths in this emerging (bio)technology. The first two sections introduce a global vision of prospecting energy from algae at the present state of knowledge while the latter two sections are focused on the Swiss context.

\section{Global Prospect of Bioenergy from Microalgae}

Microalgae have been suggested as an advantageous energy feedstock for the production of sustainable biofuels as they do not need agricultural land and thus do not compete directly with food production. Microalgae offer the opportunity to utilize land and water resources unsuited for any other use. Moreover, microalgae are amongst the most productive organisms on earth, as they attain annual productivities of 10 to 150 tons of dry biomass per hectare and an annual oil yield of approximately 100 '000 L per hectare. ${ }^{[6,7]}$ If algae are cultivated aerobically, denitrification can be strongly reduced, and hence $\mathrm{N}_{2} \mathrm{O}$ emissions are significantly lower compared to those of terrestrial crops. ${ }^{[8,9]}$ Furthermore, there is no leaking of nutrients in microalgae cultivation, which allows the efficient use of fertilizers efficiently and prevents harmful effects on the environment. ${ }^{[10]}$

The economic viability and energy efficiency of biofuels made from microalgae remain to be proved. The main obstacles to large-scale introduction of algal biofuels are the high investment costs and energy input required for microalgae cultivation and harvesting. [10,11] Successful economic production of microalgae is oriented towards specialized animal feed, nutritional supplements, or high-value molecules such as polyunsaturated fatty acids. ${ }^{[12]}$ These are all premium products that can be sold at a high price and where the energy efficiency is of minor importance.

\subsection{Requirements for the Cultivation of Microalgae}

Like any other biomass that is grown phototrophically, algae require light, water, land, $\mathrm{CO}_{2}$, and mineral nutrients for growth. Depending on the species in question, microalgae can grow in marine or freshwater environments. These parameters also define whether a given site is suitable for mass cultivation of microalgae. ${ }^{[13]}$

Light is the major limiting factor for phototrophic cultivation of microalgae.[14] The efficiency by which plants and microalgae convert light to chemical energy, the photosynthetic efficiency (PE), is rather low. ${ }^{[15]}$ The losses occur at several instances and limit the maximal theoretical PE to approximately $9 \%$. The first loss oc- curs because only light in the 400-740 nm range can be absorbed, which accounts for only $50 \%$ of the total solar energy. Even this light cannot be harvested completely, as a part is lost due to reflection and absorbance by non-functional structures. Then, only the energy equivalent of a red photon is used from every photon absorbed and further losses occur in the biochemical pathway from $\mathrm{CO}_{2}$ to sugar. Additionally, photoinhibition by too much light and photorespiration by the erroneous fixation of $\mathrm{O}_{2}$ instead of $\mathrm{CO}_{2}$ contribute to a decreasing efficiency. This explains why microalgae reach a PE of only $1.5-5 \%$ (which is still higher than the $\mathrm{PE}$ of terrestrial crops). ${ }^{[16]}$

The low PE also explains why artificial illumination is not an option if a lowcost commodity such as biofuel is to be produced and why latitude location is one of the major determining factors for siting suitable land. ${ }^{[13,17]}$ Usually arid areas are proposed as a suitable option to site largescale algae cultures not only for the high solar radiation but also to avoid competition with agriculture. ${ }^{[18,19]}$ However, this needs a careful assessment with respect to sufficient availability of water, nutrients, and $\mathrm{CO}_{2}$ as well as infrastructure.

Temperature is the second important factor that results from latitude location. Very generally, productive cultivation requires temperatures during daytime between 20-30 ${ }^{\circ} \mathrm{C}$. [20] Low temperatures slow down the cellular metabolism of the culture and become prohibitive for cultivation below $5{ }^{\circ} \mathrm{C}$. Together, this limits the cultivation season in countries such as Switzerland to the time between March and mid-October. As a consequence, the algae production needs to be paused or artificially warmed during winter.

Nutrients demand of microalgae follows their elementary composition ${ }^{[21]}$ and is substantial if cultivation is carried out on a large scale. ${ }^{[18,22]}$ The production of sufficient quantities of biofuel to match the energy requirements of a country will lead to a serious competition with agriculture for fertilizer. ${ }^{[23]}$ Hence, the use of wastewater as nutrient source and/or the recycling of nutrients is mandatory. ${ }^{[24]}$ This introduces several issues that must be addressed: Finding suitable algae strains for cultivation in wastewater, making nutrients bioavailable, preventing the accumulation of inhibiting substances, and dealing with the presence of solids, competing microorganisms, and turbidity. ${ }^{[25,26]}$

$\mathrm{CO}_{2}$ is the main carbon source if cultivation is carried out phototrophically and carbon constitutes about $50 \%$ of the microalgal biomass by weight. Mass transfer from ambient air is not sufficient for cultures of fast-growing microalgae, even if the air is sparged directly into the culture. ${ }^{[27]}$ Pure $\mathrm{CO}_{2}$ is expensive, however, and it has been shown that flue gas can be used instead without detrimental effects. ${ }^{[28]}$ Still, the provision of $\mathrm{CO}_{2}$ carries a significant cost and contributes substantially to production costs. ${ }^{[29]}$

Water is not a main driver of production costs and certainly not a critical factor in Switzerland. However, if cultivation sites in more southern regions are considered, it becomes an issue. Evaporation can reach $6 \mathrm{~L} \mathrm{~m}^{-2} \mathrm{~d}^{-1}$ in open culture systems ${ }^{[30]}$ and salinity can become critical, depending on the water used for replacement. ${ }^{[13]}$ Further, depending on the concentration of the culture at the time of harvest, a substantial amount of water is taken out of the system that must be replaced (up to $50 \%$ of the culture volume daily). [31] While direct evaporation does not occur in closed systems, they still require comparable amounts of water for external cooling. ${ }^{[32]}$ Agricultural crops have comparable values of water consumption. [33]

\subsection{Cultivation Systems}

The type of cultivation system chosen determines the productivity that can be achieved and the cost of the biofuel produced. Systems can be roughly divided in two main types: open ponds and photobioreactors.

Open ponds are cheaper to build and operate, and consume less energy per unit biofuel produced. For these reasons, open ponds are generally seen as the only option for commercial large-scale production of a low-cost commodity such as biofuel.[29] Typically, open ponds are constructed in the form of oblong raceways, about 30 $\mathrm{cm}$ deep, in which the water is circulated with paddlewheels. ${ }^{[34]}$ Harvesting is done through continuous settling followed by gravity thickening and the algae are usually further dried by sunlight. The average yield can be as high as $45 \mathrm{tha}^{-1} \mathrm{a}^{-1}{ }^{[19]}$ Open ponds are climate sensitive, the provision of $\mathrm{CO}_{2}$ is inefficient, and they are vulnerable to pollution, contamination, and predation. ${ }^{[32]}$

Photobioreactors (PBR) achieve a higher productivity and can reach higher biomass concentration than open ponds. As they are closed systems, they can be controlled more closely, which allows year-round cultivation and protection from contaminants and pests. High PE values are reported for flat-panel airlift (FPA) PBRs, ${ }^{[35]}$ which appear to be superior to tubular PBRs for the mass production of microalgae. The average yield per area is approximately $60 \%$ higher than that of open ponds, yet reported values vary widely. ${ }^{[19]}$ Despite their higher productivities, PBRs suffer from much higher investment costs (ten times higher than for open ponds) and a high energy use. 


\section{Promising Algae-to-Biofuel Routes}

Algal biomass, independent of the cultivation technique used, can be converted into biofuel via many routes. In order to situate the potential of the hydrothermal route, the whole spectrum of technological pathways is presented together with relevant information about cost, yield, input, barriers, and opportunities.

Three general categories of pathways for the conversion from microalgal biomass to fuels are widely recognized: ${ }^{[31]} \mathrm{di}-$ rect production of biofuel with algae, processing of whole algae, and processing of algal extracts (e.g. lipids or carbohydrates). The last category is not cost competitive because it requires complex treatment that involves drying, the use of solvents, and chemical conversion. ${ }^{[36,37]}$ The conversion of whole algal cells into fuels is the most interesting because of high conversion efficiencies, the avoidance of an extraction step, and the possibility to use a diverse range of algal species. ${ }^{[31,38]}$ Still, some processes require a certain level of dewatering. An overview of typical methods is presented in Fig. 1 and the discussion below addresses main pathways within each of these categories. Note that the focus is on processes that convert whole algal biomass into fuel as they are seen as most interesting due to high conversion efficiencies.

\subsection{Direct Production of Biofuels (Fermentation)}

Using appropriate cultivation conditions or genetically modified strains of microalgae, alcohols, alkanes, and hydrogen can be produced within the microalgal culture without the need of extraction from the algal biomass. A single production unit is sufficient to both cultivate algae and produce the final product, which saves costs as several processing steps are eliminated.

Direct production can take place in suitable phototrophic cultures but also using heterotrophic cultivation and fermentation techniques. Microalgae can be grown heterotrophically on organic substrates with alcohols, oils, and hydrogen being directly produced via the appropriate biochemical reactions. However, taking into account that organic substrates have to be produced themselves in a preceding step via photosynthetic processes, heterotrophic cultivation is less efficient than direct phototrophic production. ${ }^{[39]}$ Yet the technology is close to market for the production of specialty chemicals and may become competitive for biofuel if organic wastes can be used as substrate, which is theoretically possible.

\subsection{Processing of Algal Extracts}

Algal extracts such as lipids or carbohydrates that were separated from whole

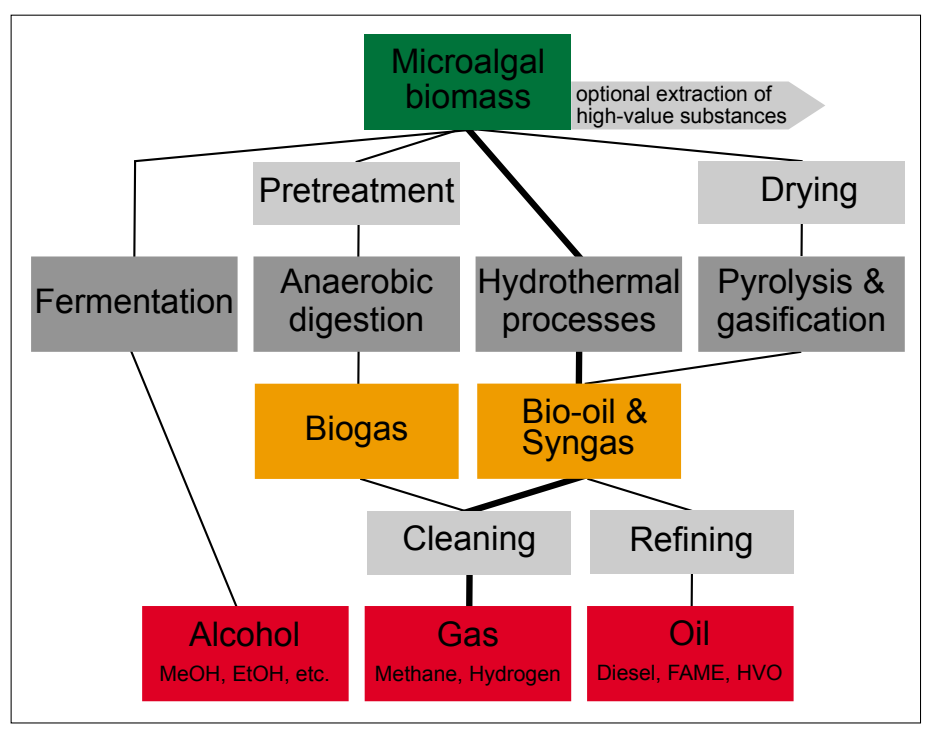

Fig. 1. Schematic of the most cost-efficient algae-to-energy conversion routes. Note that processes requiring extraction are not considered.

algal cells can be converted (refined) into usable fuels by transesterification and enzymatic and catalytic processes. Although these refining methods have limitations due their costs and conversion efficiencies (in particular when compared with methods that use thermochemical methods to convert whole algal biomass), they are well established and thus readily applicable.

The 'gold standard' among these methods is the solvent-based extraction of lipids. It is a relatively mature technology that is widely used to convert vegetable oils into biodiesel. ${ }^{[31]}$ In this process, algal cells are mechanically disrupted and lipids are extracted using a solvent (e.g. butanol or hexane). The lipids are separated from the solvent using a centrifuge and the solvent is generally reused. While this technology is proven, the costs associated with the lipid-extraction process can be prohibitive if the solvent is not fully recycled and efficiencies are not improved. A further hindrance are difficulties to achieve both high algal growth rates as well as a high oil content in the cells.

\subsection{Processing of Whole Algae}

Whole algal biomass can be processed using three main routes: anaerobic digestion, thermal processes, and hydrothermal processes (see Table 1 for a comparative summary).

Anaerobic digestion is a commercially available technology that can also be used to convert microalgal biomass into methane. ${ }^{[43]}$ The complete process is driven by microorganisms and begins with an initial hydrolysis of the biomass. Acidogenic bacteria then convert sugars and amino acids into carbon dioxide, hydrogen, ammonia, and organic acids. Finally, methanogens convert these products to methane and carbon dioxide. The technology can be used to convert whole algae (grown to be rich in carbohydrates) but is also suggested for raffinates (e.g. after the extraction of oil).
Methane can be either injected into a gas grid or be used to produce electricity on site via cogeneration. Nutrients in the digestate that is left over after anaerobic digestion process can be fed back into the algae cultivation process, as well as $\mathrm{CO}_{2}$ (flue gas) and waste heat from cogeneration. ${ }^{[43]} \mathrm{An}$ economically successful integration of microalgae cultivation will depend on the configuration of the complete process (i.e. digestion of whole algal biomass or algal residues), choice of algal species, pretreatment (to improve digestibility and reduce hydraulic retention time), ${ }^{[44]}$ and nutrient recycling. ${ }^{445,46]}$

Thermal processes break down organics under high temperatures. Pyrolysis is a process in which biomass is degraded in the absence of oxygen to produce char (or ash), oil and synthesis gas (syngas). Gasification then breaks down the hydrocarbons left into the syngas using a controlled amount of oxygen. Conventional pyrolysis operates at relatively low temperatures and produces mainly biochar that is used as active carbon, fertilizer, and soil amendment agent. Fast pyrolysis is conducted under a high heating rate and short residence time with rapid cooling of gas products. ${ }^{[4]}$ To convert biomass to syngas through gasification, partial oxidation reactions occur at temperatures between 700-1100 ${ }^{\circ} \mathrm{C} .{ }^{[48]}$ Post-treatment of syngas provides a flexible means to serve various energy markets (e.g. liquid fuels via Fischer-Tropsch synthesis). ${ }^{[49,50]}$ Catalytic reforming or fermentation to chemicals is often coupled with gasification processes. A key barrier to this method is the requirement for biomass of an energy intense drying prior to conversion, which reduces the overall efficiency to uneconomic levels. Also, in the case of producing bio-oil from pyrolysis, its components are very complex and upgrading is required.[31]

Hydrothermal processes use near critical or supercritical water as reaction 
Table 1. Comparison of main routes by which microalgal biomass can be converted into biofuel.

\section{Anaerobic digestion Thermal processes}

Input
Yield (as
energy effi-
ciency)

Costs (in gasoline equivalents)

Residence
time

Wet feedstock (pretreatment is indicated)

Up to $35 \%$ $\sim 56 \%$

Dry feedstock

Hydrothermal processes

Wet feedstock

When biomethane is upgraded: CHF 0.50-0.70/L ${ }^{[40]}$

Minimum selling
price: CHF 2.90/L

SCWG conversion costs: CHF 3.60/L $\mathrm{L}^{[42]}$

$\mathrm{CH}_{4}$ production costs: CHF 8.30/L ${ }^{[42]}$ $<30 \mathrm{~min}$

$$
\text { 2-4 weeks }
$$

$<10 \min$

\section{Barriers}

Slow reaction, low efficiency, pretreatment and cosubstrates required, residues

Opportunities Proven technology, low capital cost

Energy intense drying, production separation and purification (pyrolysis)

Mature technology

Full conversion with high efficiency, no drying and pretreatment of the feed required, sterile residues

Complexity

Low

High first-generation biodiesel routes from food crops such as rape or soy. ${ }^{[46]}$ When biosyngas generation from hydrothermal processes is considered as the main route for a Swiss case, it becomes obvious that the main economic barrier is the cultivation of algae itself and not the conversion pathway. ${ }^{[42,55,56]}$ The following sections summarize these techno-economic studies, in particular the work by Brandenberger and colleagues, ${ }^{[42]}$ which is to our knowledge the only study that considers a Swiss case for both the cultivation of microalgae and the subsequent hydrothermal conversion of biomass to SNG.

\subsection{Energy Consumption Analysis}

The energy efficiency of a feedstockto-biofuel process is generally expressed using the energy return on energy invested (EROEI) performance indicator, which can be defined as follows: ${ }^{[42]}$

EROEI $=\frac{\text { Usable acquired energy }}{\text { Energy expended }}=\frac{E_{S N G}}{E_{\text {input }}}$

$E_{\text {input }}$ sums all input energy required for the process. The EROEI in Brandenberger's work $^{[42]}$ assumes that electric power needs are satisfied directly from within the process (no combination with other renewable systems, as often reported). Open ponds systems scored a more favorable EROEI than FPA-PBRs (Fig. 2), with air blowers being responsible for the lower EROEI of the latter.

Sensitivity analysis that was performed to identify parameters that have a strong effect on EROEI calculations revealed air blowers and biomass productivity as being critical. When biomass productivity was raised by $50 \%$ (optimistic case) or by $100 \%$ (very optimistic case), estimates for annual production reached $58-77 \mathrm{t} \mathrm{ha}^{-1}$ for open ponds and 119-158 $\mathrm{t} \mathrm{ha}^{-1}$ for FPA- reforming of organics and the methanation reactions. ${ }^{[52]}$ The advantages of hydrothermal processes are multiple: Residence time is very short (minutes), ${ }^{[53]}$ which reduces the footprint of a processing facility and allows a rapid response to changes in demand. Because water is the reaction medium, neither biomass drying is necessary nor the use of organic solvents. Finally, high process efficiencies (up to $70 \%$ ) can be achieved. [54]

Undoubtedly, further research and development is required until the decision for the best algae-to-biofuel conversion technology can be made. However, the comparison provided here emphasizes the potential of the hydrothermal route, in particular when wet feedstock such as microalgae is to be processed. It avoids energy and cost intensive steps like drying for thermal processes or pretreatment of the feed for anaerobic digestion and exhibits

\section{Techno-economics of Algae-to- Biogas Routes in a Swiss Scenario}

The overall energy efficiency is higher when biogas (or syngas) is produced instead of biodiesel, even when compared to
Fig. 2. EROEl of electricity production via hydrothermal processes using either flat-panel PBRs (FPA-PBR) or open raceway-type ponds. Shadings indicate base case (light green), optimistic (mid green), and very optimistic (dark green) scenarios (data from ref. [42]). The EROEI does not include the initial construction of the facilities. 
PBRs. This would reflect PEs between $2.6 \%$ and $3.5 \%$ for open ponds and between $5.4 \%$ and $7.2 \%$ for FPA-PBRs (using solar irradiance for Switzerland) which is close to the maximum theoretical PE for microalgae. The authors concluded that it would be more realistic to lower the energy demand for algae cultivation instead of increasing productivity as both impact equally on the EROEI. They showed for a very optimistic scenario an energy efficiency of 5.8 for self-sufficient systems using open ponds (Fig. 2). In that case, the electricity required for the microalgae cultivation and for the hydrothermal plant auxiliaries (e.g. pumps) needs to be produced by converting part of the syngas with a modern combined cycle gas turbine technology that has an estimated conversion efficiency of $55 \%$.

Total energy efficiencies were also calculated in the frame of the SunCHem project but considering a production site in the north-east region of Brazil.[55] Taking into account all process steps (cultivation, dewatering, gasification, and product purification), EROEI ranged between 5.2 and 5.8, which is very high for a biomass conversion system. This can be attributed not only to a high PE but also to the high carbon conversion ratio (around $75 \%$ ) of the biomass-to-SNG process. Electricity demand of cultivation and dewatering accounted for $\sim 6 \%$ of the energy in the biomass produced, which is an optimistic value that was reached by assuming that the best available technology on the market is used.

A parallel study by the same authors provided also a benchmark of the process with the thermo-chemical conversion of lignocellulosic biomass. ${ }^{[56]}$ Several biofuels were included in the analysis and it was shown that the SunChem process benefits from the high PE of microalgae ${ }^{[57]}$ when compared to wood conversion through gasification and fuel synthesis. Microalgae production using open pond and hydrothermal gasification for conversion into a methane-rich syngas is more efficient.

\subsection{Economic Analysis}

In view of the high production costs for algal biomass and thus for algal biofuels, an economic analysis has been additionally provided in the work by Brandenberger et al., ${ }^{[42]}$ which was based on both capital and operating costs and assumed different steps of technological improvement. The base case scenario showed that cultivation of microalgae accounted for more than $95 \%$ of the investment costs and $40 \%$ to $55 \%$ of the production costs. Wages are a key for the optimization of the complete production route, and it has been suggested that there is more potential for reduction of labor costs when FPA-PBRs are used instead (Fig. 3). ${ }^{[42]}$ This has been attrib-

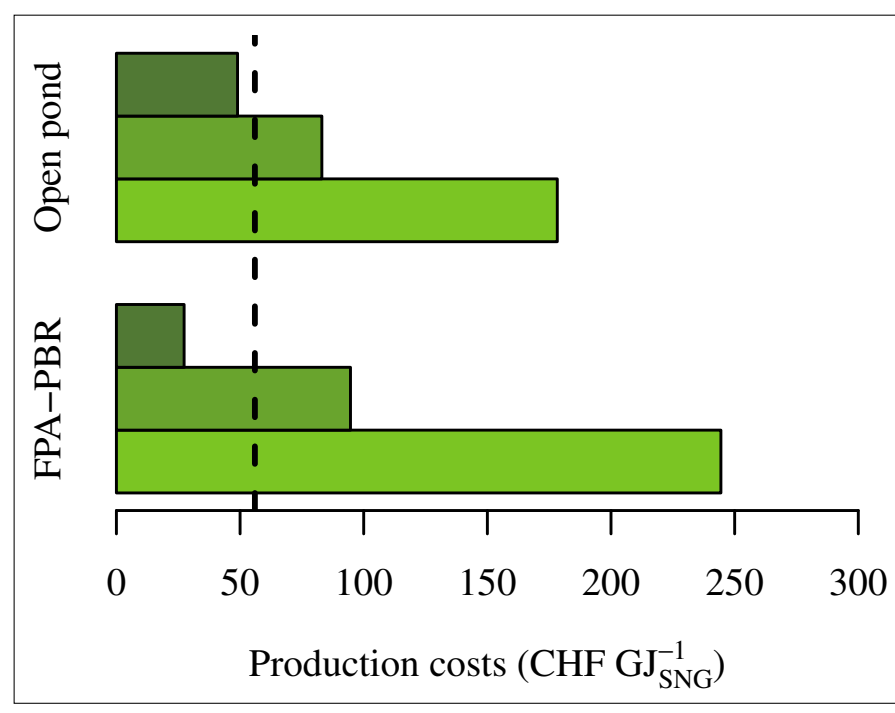

Fig. 3. SNG production costs via hydrothermal processes using either flat-panel PBRs (FPA$\mathrm{PBR}$ ) or open racewaytype ponds. Shadings indicate base case (light green), optimistic (mid green), and very optimistic (dark green) scenarios (data from ref. [42]). The limit of 56 $\mathrm{CHF} \mathrm{GJ} \mathrm{SNG}^{-1}$ (assumed as an upper target price for biogas ${ }^{[58]}$ ) is indicated by the dashed line. The numbers include investment costs (depreciation within 15 years)

uted to the large areal differences between the two cultivation systems, an assumption that is debatable and may lead to an overestimation of the costs in the case of open ponds. A further difference between the two production systems is the biomass concentration at harvest, which is lower for open ponds and hence requires expensive dewatering equipment.

One of the authors (D. R.) has conducted an economic analysis as contract work that focused on the production of animal feed from microalgae in Switzerland (data available on request). While the study considered only PBRs for the cultivation of microalgae, its results nevertheless corroborate the findings of Brandenberger $e t$ $a l .{ }^{[42]}$ in that the price of land, erection of the cultivation system, and labor costs are the main factors that determine the price of microalgal biomass. The next largest item is the cost of $\mathrm{CO}_{2}$. Sparging $\mathrm{CO}_{2}$ into the algae culture greatly increases productivity, yet for its delivery to be economic, a source must be located nearby.[29]

In summary, the cultivation of microalgae has a net energy balance that is positive, even in the Swiss climate, and cultivation in open ponds is energetically more favorable than in PBRs. However, the fact that land and wages are high in Switzerland poses a great barrier to the economic production of microalgae. As long as these factors remain the major obstacle, any optimization of the cultivation will not be able to reduce the costs to the typical biogas price range in Switzerland (when addressed for standard applications, e.g. household installation) of 15 to $20 \mathrm{Rp} . /$ $\mathrm{kWh}$ equivalent to approximately 42 to 56 CHF/GJ.[58]

That aside, the cultivation of microalgae has an enormous potential for optimization from several angles: Novel harvesting technologies, novel reactor materials and designs, automation of the production, prospecting and engineering of highly productive algal strains, or efficient pest control.

\section{Limitations and Opportunities in a Swiss Framework}

Microalgae are often heralded as superorganisms with yields that surpass those of all other crops by an order of magnitude. While it is true that algae have a comparatively high solar energy conversion efficiency, this efficiency is bought dearly by an engineered growing environment and an external energy input during cultivation. Once harvested, dry matter content is very low and processing of the biomass is expensive. Research progress will lower production costs for the cultivation of microalgae in the future. However, other factors that contribute to costs are not likely to change and do not favor the large-scale production of algal biofuel in Switzerland. Solar irradiation is comparatively moderate and there are pronounced seasons with cold winters. High land prices and wages further hinder a large-scale production of low-cost commodities. The production of Swiss-made algal fuel would be at least twice as expensive as its production in more favorable regions such as Southern Europe, North Africa or Turkey. Even with the prospect of becoming energy independent it is doubtful whether this can be justified. Table 2 gives an overview of opportunities and barriers for the commercial production of microalgae in Switzerland.

So why should Switzerland engage in the development of algae-based biofuel production routes? It is the excellent environment for research and development that puts Switzerland in the position to make following most important challenges: i) engineering of algal strains with properties that improve productivity, facilitate processing or enhance robustness, ii) mansignificant contributions. We identify the 
Table 2. List of factors that either present opportunities for the commercial cultivation of algal biomass or that hinder its development.

\section{Opportunities for the cultivation of microalgae \\ $\mathrm{CO}_{2}$ uptake}

Cost of electricity and water

Biomass concentration

Land

Energy consumption The major part of the energy demand for cultivation is for mixing. In flat-panel PBRs, the energy input for $\mathrm{CO}_{2}$ mass transfer and mixing with air blowers accounts for $89 \%$ of the total energy consumption. In open ponds, mixing by paddle wheels consumes $63 \%$ of the total required energy. ${ }^{[42]}$

Labour costs

Seven persons are required to operate an open pond cultivation facility of 100 ha. ${ }^{[60]}$ Wages in Switzerland are twice as high as in Spain and ten times higher as in Romania and may account for $10-45 \%$ of the production costs. ${ }^{[42]}$

agement of pests that threaten microalgal cultures, iii) integration of cultivation processes with waste streams to close nutrient cycles, and iv) development of advanced conversion technologies (e.g. hydrothermal gasification). Gaining know-how and developing technologies in these fields will open export markets and allow Swiss companies to become shareholders in an emerging global biotechnology.

\section{Outlook on Research Trends}

The research trends presented here are not exhaustive. They represent examples, where the authors identify opportunities for Switzerland to make substantial contributions.

\subsection{Using the Complete Solar Spectrum for Energy Production}

The largest drop in solar energy conversion efficiency occurs due to the inability of microalgae to absorb light with wavelengths outside of the 400-700 nm range (photosynthetically active radiation PAR), which accounts for approximately $50 \%$ of the solar energy. By covering a microalgae cultivation system with translucent dye-sensitized solar cells that absorb wavelengths outside of the PAR range (i.e. in the infra-red and blue region), the complete spectrum of solar radiation can be used. [61] As the incoming light is filtered before reaching the microalgal culture, the conversion efficiency of the latter is effectively doubled.

\subsection{Closing Nutrient Cycles and Using Waste Streams}

Currently, most commercial algae cultivation plants buy $\mathrm{CO}_{2}$ and chemical fertilizers for their production needs. For algal biofuels to meet the life cycle emissions reduction threshold of $60 \%$ (compared to fossil fuel) set by the EU Renewable Energy Directive, energy and material inputs must be reduced. Recycling of nutrients (or recovering them from waste streams), use of industrial waste heat, and sourcing $\mathrm{CO}_{2}$ from flue gas that would otherwise be vented contributes both to meeting the emissions threshold and to lowering costs. At the same time this improves the ecological footprint of the integrated technologies.

As outlined above, anaerobic digestion (i.e. biogas plants) or hydrothermal methanation of wet biomass lend themselves to such an integrative approach. ${ }^{[46]}$ While several parts of this approach have already been studied in similar or different contexts, e.g. the use of flue gas instead of pure $\mathrm{CO}_{2}{ }^{[28]}$ or wastewater as growth medium, ${ }^{[35]}$ a pilot-scale setup that allows long-term studies is now required to investigate practical and economical feasibility. The insights gained will benefit any largescale cultivation of microalgae, irrespective of the product that is pursued. 


\subsection{Understanding the Ecology of Mass Cultures to Improve Productivity and Control Pests}

Mass cultures of microalgae in open facilities are very susceptible to environmental challenges such as infection by pathogens or predation by zooplankton. ${ }^{[14]}$ The homogenous environment of the open pond, the low genetic diversity of the microalgal culture, and its high density allow an infestation to spread rapidly and quickly cause devastating losses. ${ }^{[62]}$ In order to be able to detect and subsequently control these often novel biological contaminants, diagnostic tools and treatment methods must be developed. ${ }^{63,64]}$

A further area of research that relates to this topic is the concept of synthetic ecology, which posits that the insights gained from studies of natural ecosystems can be applied to engineer microalgal cultures such that they become more robust and more productive. ${ }^{[65]}$ A prominent example is the relationship between biodiversity and productivity in an ecosystem, which suggests that microalgal polycultures may be more productive than monocultures. ${ }^{[66]}$ In addition, they may be less vulnerable to attack by predators and parasites. Whether these ecological tenets can be applied to the mass cultivation of microalgae is largely untested.

\subsection{A Biorefinery Approach?}

The high market value of certain algae components has led to the proposition of a biorefinery concept in which high value products are extracted first, while the remaining organic 'waste' could subsequently be used for low value commodities, i.e. feed and fuel (Fig. 4). ${ }^{[67]}$ In theory, the biorefinery concept is attractive. In practice many barriers have to be overcome such as constant feedstock quality and supply. In several EU-funded projects (BioFAT, PUFAChain, AlgaePARC, and EUALGAE), various biorefinery concepts are being explored and their results will give more insights in their feasibility in the coming years.

Optimizing algae supply chains for their end-product gives the most attractive business case. ${ }^{[29]}$ Therefore, the vision we share is that of promoting synergies e.g. between the fine chemicals sector and that of energy. The algae residues left once the end product reached can be recovered as the feed material for the algal energy process.

\section{Concluding Remarks}

The success of algal fuels depends on cost savings, a more efficient cultivation, and the price of competing products. While techno-economic studies and re-

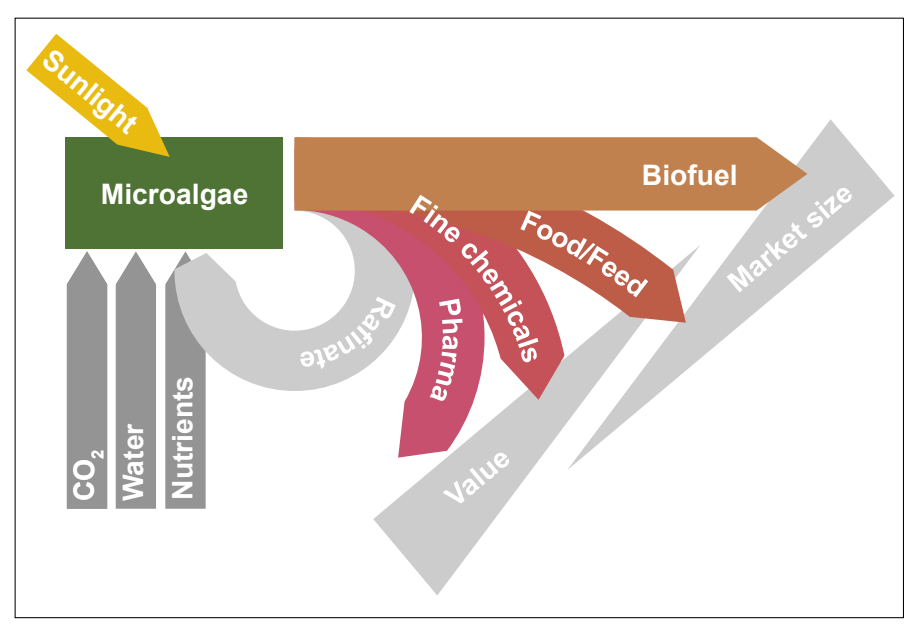

Fig. 4. Simplified scheme of an algal biorefinery concept. Ideally, production pathways of different commodities do not compete and waste streams can be recycled, thus lowering production costs and ecological footprint.

search trends project that eventually algal fuels can be produced competitively, they remain misty concerning an exact roadmap and time frame. More importantly however, the EROEI of biofuel from microalgae is clearly above one. SNG remains a very versatile algae product that can be used for heating, power generation, and as transportation fuel. Currently no other renewable energy is economically competitive with bio-methane when used for transportation. Further, there is readiness for an efficient distribution of SNG to the customer through the natural gas grid. There is momentum in research and opportunities for demonstration thanks to the significant private and public investment globally. Swiss R\&D could certainly add value to the global research landscape and extract value from future global breakthroughs that are not only restricted to fuels.

\section{Acknowledgments}

The authors are grateful for the financial support from the Commission of Technology and Innovation CTI (project SCCER BIOSWEET), the Competence Center Energy and Mobility CCEM, and Swisselectric Research (project PAWaSto).

Received: August 13, 2015

[1] 12.079 - Message relatif au plan d'action 'Recherche énergétique suisse coordonnée' - Mesures pour les années 2013 à 2016, https://www.admin.ch/opc/fr/federalgazette/2012/8331.pdf, accessed August 13, 2015.

[2] B. Steubing, R. Zah, P. Waeger, C. Ludwig, Renew. Sustain. Energy Rev. 2010, 14, 2256.

[3] SCCER-BIOSWEET, http://www.sccerbiosweet.ch/, accessed August 13, 2015.

[4] S. Stucki, F. Vogel, C. Ludwig, A. G. Haiduc, M. Brandenberger, Energy Environ. Sci. 2009, 2, 535 .

[5] www.news.admin.ch - Energiewende in Reinkultur - in Wädenswil zu bestaunen, https://www.news.admin.ch/message/index. html?lang $=$ de \& msg-id $=54384, \quad$ accessed August 13, 2015.

[6] L. Brennan, P. Owende, Renew. Sustain. Energy Rev. 2010, 14, 557
[7] C. Griehl, S. Bieler, C. Posten, in 'Renewable Energy', Eds. R. Wengenmayr, T. Bührke, Wiley-VCH, Weinheim, 2012, p. 79.

[8] L. Batan, J. Quinn, B. Willson, T. Bradley, Environ. Sci. Technol. 2010, 44, 7975.

[9] K. D. Fagerstone, J. C. Quinn, T. H. Bradley, S. K. De Long, A. J. Marchese, Environ. Sci. Technol. 2011, 45, 9449.

[10] A. F. Clarens, E. P. Resurreccion, M. A. White, L. M. Colosi, Environ. Sci. Technol. 2010, 44, 1813.

[11] J. B. van Beilen, Biofuels Bioprod. Biorefining 2010, $4,41$.

[12] P. Spolaore, C. Joannis-Cassan, E. Duran, A. Isambert, J. Biosci. Bioeng. 2006, 101, 87.

[13] E. R. Venteris, R. C. McBride, A. M. Coleman, R. L. Skaggs, M. S. Wigmosta, Environ. Sci. Technol. 2014, 48, 3559.

[14] A. Richmond, in 'Handbook of Microalgal Culture: Biotechnology and Applied Phycology', Ed. A. Richmond, Blackwell, Oxford, 2004, p. 125.

[15] X.-G. Zhu, S. P. Long, D. R. Ort, Curr. Opin. Biotechnol. 2008, 19, 153.

[16] Y. Chisti, in 'Microalgal Biotechnology: Integration and Economy', Eds. C. Posten, C. Walter, De Gruyter, Berlin, 2012, p. 113.

[17] W. Blanken, M. Cuaresma, R. H. Wijffels, M. Janssen, Algal Res. 2013, 2, 333.

[18] R. H. Wijffels, M. J. Barbosa, Science 2010, 329, 796.

[19] M. R. Tredici, in 'Handbook of Microalgal Culture: Biotechnology and Applied Phycology', Ed. A. Richmond, Blackwell, Oxford, 2004, p. 178.

[20] Y. Chisti, Trends Biotechnol. 2008, 26, 126.

[21] Energy research Centre of the Netherlands - Phyllis2, database for biomass and waste, https://www.ecn.nl/phyllis2, accessed August 13, 2015.

[22] C. E. Canter, P. Blowers, R. M. Handler, D. R. Shonnard, Appl. Energy 2015, 143, 71.

[23] R. Pate, G. Klise, B. Wu, Appl. Energy 2011, 88, 3377.

[24] J. K. Pittman, A. P. Dean, O. Osundeko, Bioresour. Technol. 2011, 102, 17.

[25] J. de la Noüe, G. Laliberté, D. Proulx, J. Appl. Phycol. 1992, 4, 247.

[26] L. Christenson, R. Sims, Biotechnol. Adv. 2011, $29,686$.

[27] L. M. Brown, Energy Convers. Manag. 1996, 37, 1363.

[28] J. Doucha, F. Straka, K. Lívanský, J. Appl. Phycol. 2005, 17, 403.

[29] J. Benemann, Energies 2013, 6, 5869.

[30] J. Doucha, K. Lívanský, in 'Algal Biorefineries', Eds. R. K. Baipai, A. Prokop, M. Zappi, Springer, Berlin, 2013, p. 147

[31] J. Ferell, V. Sarisky-Reed, 'National Algal Biofuels Technology Roadmap', U.S. Departement of Energy, 2010. 
[32] J. C. M. Carvalho, M. C. Matsudo, R. P. Bezerra, L. S. Ferreira-Camargo, S. Sato, in 'Algal Biorefineries', Eds. R. K. Baipai, A. Prokop, M. Zappi, Springer, Berlin, 2013, p. 83

[33] P. Steduto, T. C. Hsiao, E. Fereres, D. Raes, 'Crop Yield Response to Water', FAO, Rome, 2012.

[34] R. Ravikumar, in 'Algal Biorefineries', Eds. R. K. Baipai, A. Prokop, M. Zappi, Springer, Berlin, 2013, p. 127.

[35] M. Bagnoud-Velásquez, U. Schmid-Staiger, G. Peng, F. Vogel, C. Ludwig, Algal Res. 2015, 8 , 76.

[36] L. Lardon, A. Hélias, B. Sialve, J.-P. Steyer, O. Bernard, Environ. Sci. Technol. 2009, 43, 6475.

[37] L. F. Razon, R. R. Tan, Appl. Energy 2011, 88, 3507.

[38] A. G. Haiduc, M. Brandenberger, S. Suquet, F. Vogel, R. Bernier-Latmani, C. Ludwig, J. Appl. Phycol. 2009, 21, 529.

[39] Y. Chisti, Biotechnol. Adv. 2007, 25, 294.

[40] International Renewable Energy Agency, 'Road transport: the cost of renewable solutions', IRENA, Bonn, 2013.

[41] S. Jones, J. Holladay, C. Valkenburg, D. Stevens, C. Walton, C. Kinchin, D. C. Elliott, S. Czernik, 'Production of gasoline and diesel from biomass via fast pyrolysis, hydrotreating and hydrocracking: a design case', Pacific Northwest National Laboratory, Richland, 2009.
[42] M. Brandenberger, J. Matzenberger, F. Vogel, C. Ludwig, Biomass Bioenergy 2013, 51, 26.

[43] B. Sialve, N. Bernet, O. Bernard, Biotechnol. Adv. 2009, 27, 409.

[44] M. Ras, L. Lardon, S. Bruno, N. Bernet, J.-P. Steyer, Bioresour. Technol. 2011, 102, 200.

[45] C. González-Fernández, B. Sialve, N. Bernet, J. P. Steyer, Bioresour. Technol. 2012, 110, 610.

[46] P. Collet, A. Hélias, L. Lardon, M. Ras, R.-A. Goy, J.-P. Steyer, Bioresour. Technol. 2011, 102, 207.

[47] D. Mohan, Charles U. Pittman, P. H. Steele, Energy Fuels 2006, 20, 848.

[48] A. Demirbaş, Energy Sources Part Recovery Util. Environ. Eff. 2006, 28, 933.

[49] K. Okabe, K. Murata, M. Nakanishi, T. Ogi, M. Nurunnabi, Y. Liu, Catal. Lett. 2008, 128, 171.

[50] S. Srinivas, R. K. Malik, S. M. Mahajani, Energy Sustain. Dev. 2007, 11, 66.

[51] M. J. Antal, S. G. Allen, D. Schulman, X. Xu, R J. Divilio, Ind. Eng. Chem. Res. 2000, 39, 4040.

[52] D. C. Elliott, L. J. Sealock, E. G. Baker, Ind. Eng. Chem. Res. 1993, 32, 1542.

[53] O. Yakaboylu, J. Harinck, K. G. Smit, W. de Jong, Energies 2015, 8, 859.

[54] J. S. Luterbacher, M. Fröling, F. Vogel, F. Maréchal, J. W. Tester, Environ. Sci. Technol. 2009, 43, 1578 .

[55] A. Mian, A. V. Ensinas, F. Marechal, Comput. Chem. Eng. 2015, 76, 170

[56] A. V. Ensinas (personal communication), Universidade Federal do ABC
[57] D. F. Westlake, Biol. Rev. 1963, 38, 385

[58] StWZ Energie, http://www.stwz.ch/de/home, accessed August 13, 2015.

[59] Paul Scherrer Institut, Energ. Spieg. 2012, 21, 6

[60] N.-H. Norsker, M. J. Barbosa, M. H. Vermuë, R. H. Wijffels, Biotechnol. Adv. 2011, 29, 24.

[61] Competence Center Energy and Mobility CCEM, 'CCEM - Annual Activity Report 2014', Paul Scherrer Institut, Villigen, 2015.

[62] J. B. Shurin, R. L. Abbott, M. S. Deal, G. T. Kwan, E. Litchman, R. C. McBride, S. Mandal, V. H. Smith, Ecol. Lett. 2013, 16, 1393.

[63] A. M. Collins, H. D. T. Jones, R. C. McBride, C. Behnke, J. A. Timlin, Biotechnol. Bioeng. 2014, 111,1748

[64] P. M. Letcher, S. Lopez, R. Schmieder, P. A Lee, C. Behnke, M. J. Powell, R. C. McBride, PLOS ONE 2013, 8, e56232.

[65] E. Kazamia, D. C. Aldridge, A. G. Smith, J. Biotechnol. 2012, 162, 163.

[66] B. J. Cardinale, K. L. Matulich, D. U. Hooper, J. E. Byrnes, E. Duffy, L. Gamfeldt, P. Balvanera, M. I. O'Connor, A. Gonzalez, Am. J. Bot. 2011, 98, 572.

[67] H.-W. Yen, I.-C. Hu, C.-Y. Chen, S.-H. Ho, D.J. Lee, J.-S. Chang, Bioresour. Technol. 2013, $135,166$. 